\title{
GEOGRAFÍA DE AMÉRICA
}

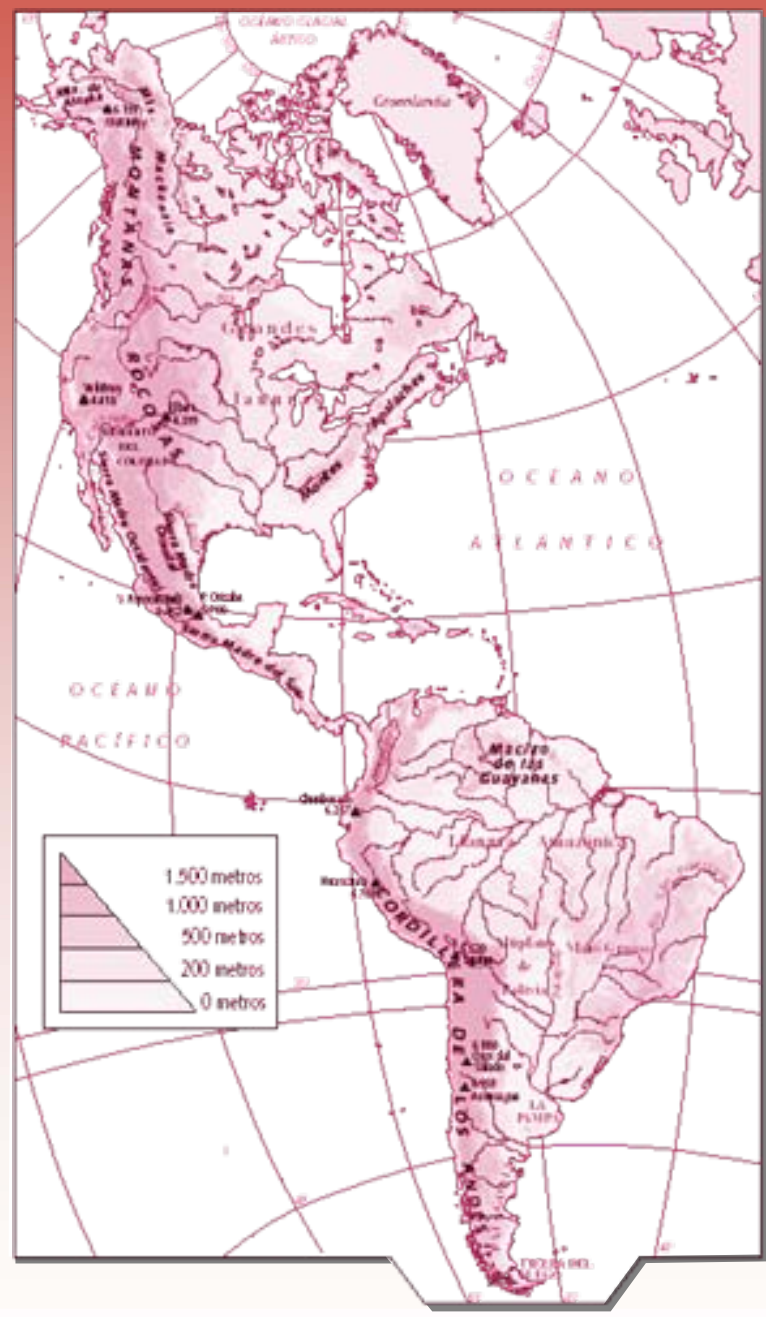

\section{REGIÓN. CONCEPTO CRÍTICO PARA SU DELIMITACIÓN. TIPOS DE REGIONES}

\author{
Prof. Jorge Alfredo ALBERTO \\ Prof. Marcelo Aníbal MIGNONE
}

MATERIAL DE CONSULTA DE CÁTEDRA

ELABORACIÓN PROPIA A PARTIR DE LA COMPILACIÓN DE BIBLIOGRAFÍA IMPRESA Y DE INTERNET

- Profesorado y Licenciatura en Geografía

- Departamento de Geografía

- Facultad de Humanidades

- Universidad Nacional del Nordeste

Publicado en formato digital: Prof. Jorge Alfredo ALBERTO y Prof. Marcelo Aníbal MIGNONE. REGIÓN. CONCEPTO CRÍTICO PARA SU DELIMITACIÓN. TIPOS DE REGIONES. Resúmenes. Revista Geográfica Digital.IGUNNE. Facultad de Humanidades. UNNE. Año 9 . N017. Enero -Junio 2012. 


\section{OBJETIVOS DE LA CÁTEDRA}

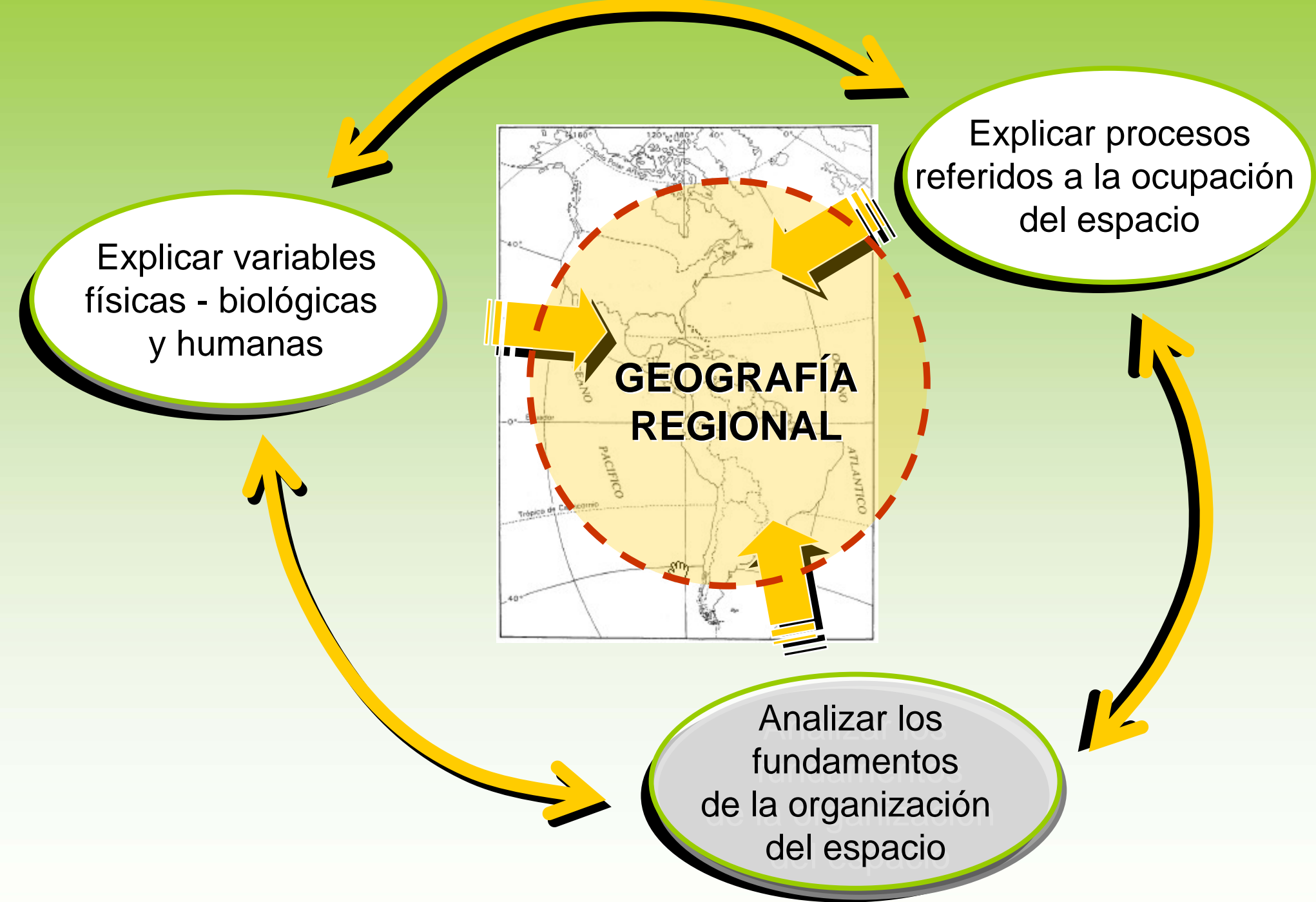

Publicado en formato digital: Prof. Jorge Alfredo ALBERTO y Prof. Marcelo Aníbal MIGNONE. REGIÓN. CONCEPTO CRÍTICO PARA SU DELIMITACIÓN. TIPOS DE REGIONES. Resúmenes. Revista Geográfica Digital.IGUNNE. Facultad de Humanidades. UNNE. Año 9. №17. Enero -Junio 2012. 


\section{El objetivo principal de la asignatura consiste en iniciar al alumno en el conocimiento y comprensión de dinámica regional del continente Americano.}

Con ello se pretende:

- por un lado, que al alumno reconozca y comprenda los procesos fundamentales que intervienen en la conformación de los espacios regionales y de las relaciones dinámicas que se establecen entre ellos, y

- por otro, que identifique y entienda las dimensiones temporales y espaciales de las variables físicas, sociopolíticas y económicas que configuran la diversidad regional de América. 


\section{OBJETIVOS DE LAS ACTIVIDADES DE LA CÁTEDRA}

\section{Aplicar técnicas y métodos de la Geografía Regional al estudio del continente americano.}

Que el alumno logre:

Transferir contenidos básicos a la solución de situaciones problemáticas.

- Usar correctamente el vocabulario técnico geográfico en el estudio del análisis regional.

- Brindar una aproximación sobre la organización regional del continente americano.

ORGANIZACIÓN DE LA CATEDRA

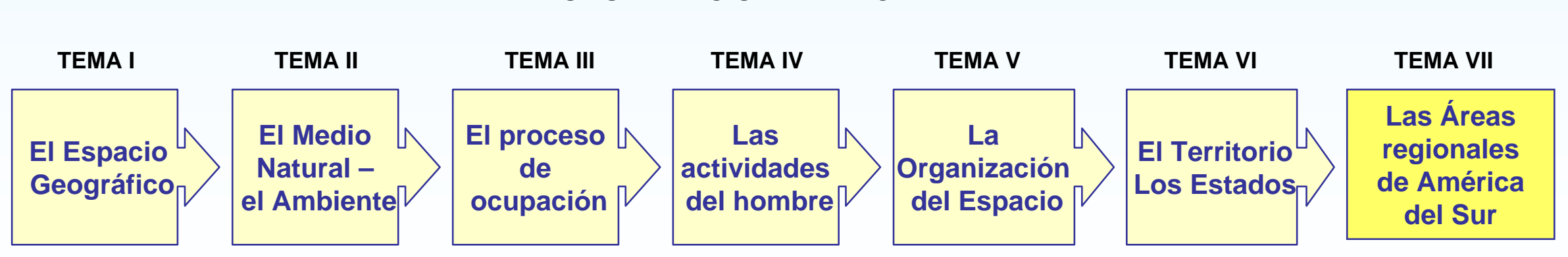




\section{DEFINICIONES DE REGIÓN}

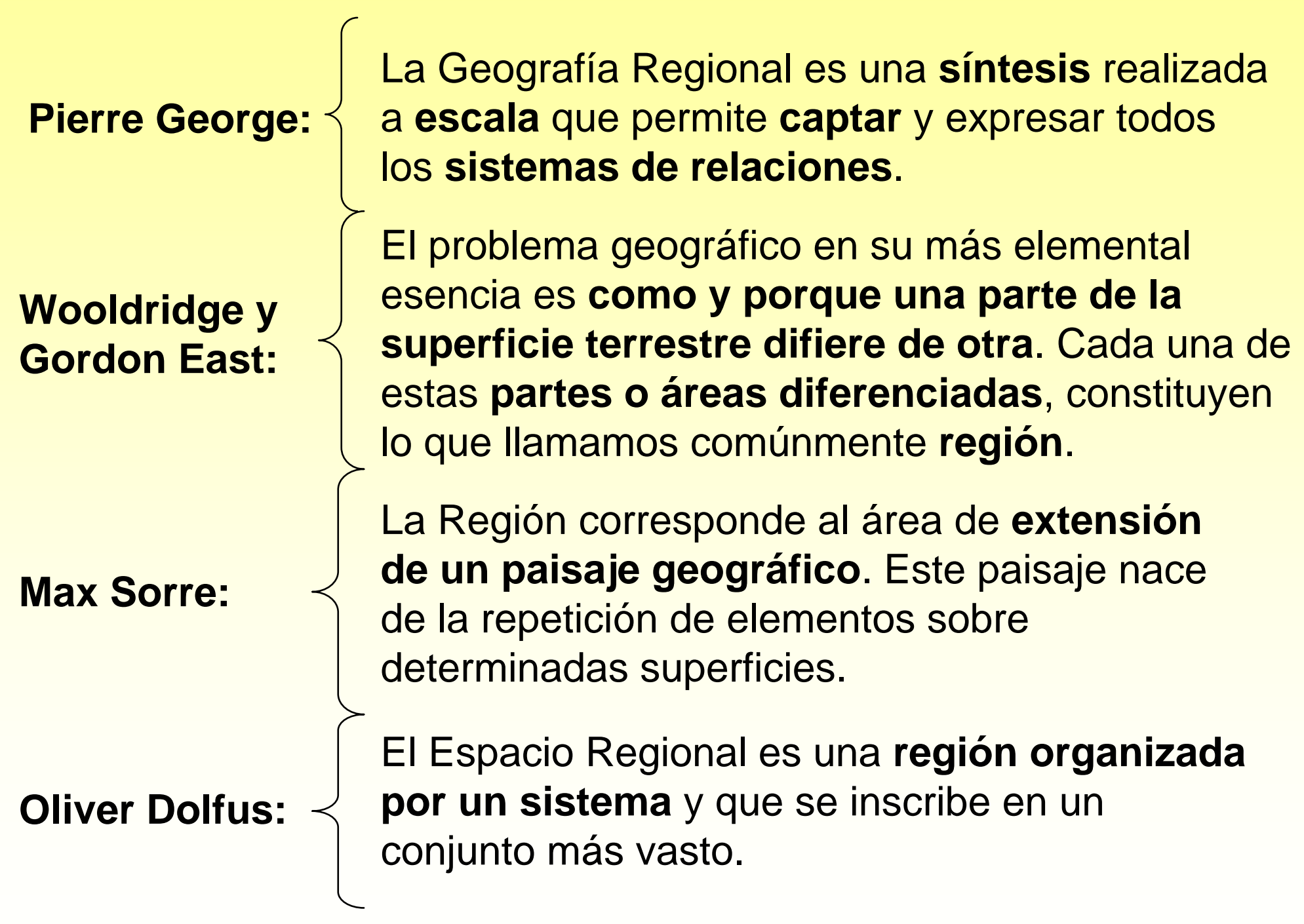


IG Revista Geográfica Digital. IGUNNE. Facultad de Humanidades. UNNE. Año 9. N’17. Enero - Junio 2012. ISSN 1668-5180 Resistencia, Chaco

\section{TIPOS DE REGIONES}

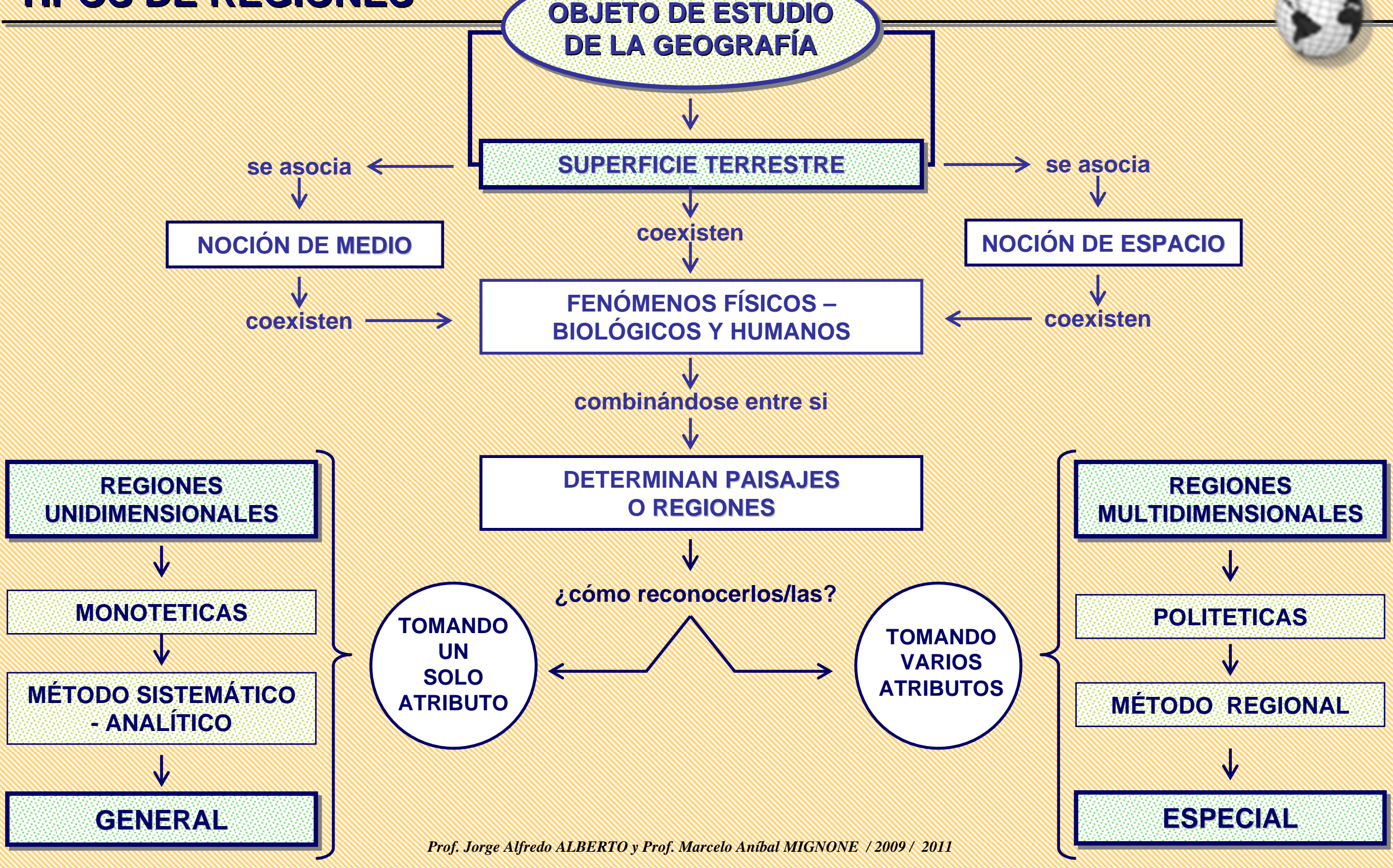

Publicado en formato digital: Prof. Jorge Alfredo ALBERTO y Prof. Marcelo Aníbal MIGNONE. REGIÓN. CONCEPTO CRÍTICO PARA SU DELIMITACIÓN. TIPOS DE REGIONES. Resúmenes. Revista Geográfica Digital.IGUNNE. Facultad de Humanidades. UNNE. Año 9. No17. Enero - Junio 2012.

Resistencia, Chaco. En: http://hum.unne.edu.ar/revistas/geoweb/default.htm 


\section{Whittlesey $>$ Establece REGIONES.}

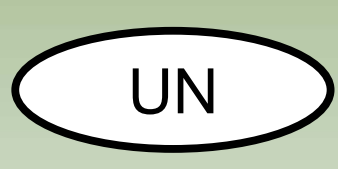

\section{Cantidad CARACTERES}

\section{TODOS}

REGIONES

REGIONES CON CARACTERÍSTICAS ÚNICAS O GENÉRICAS 

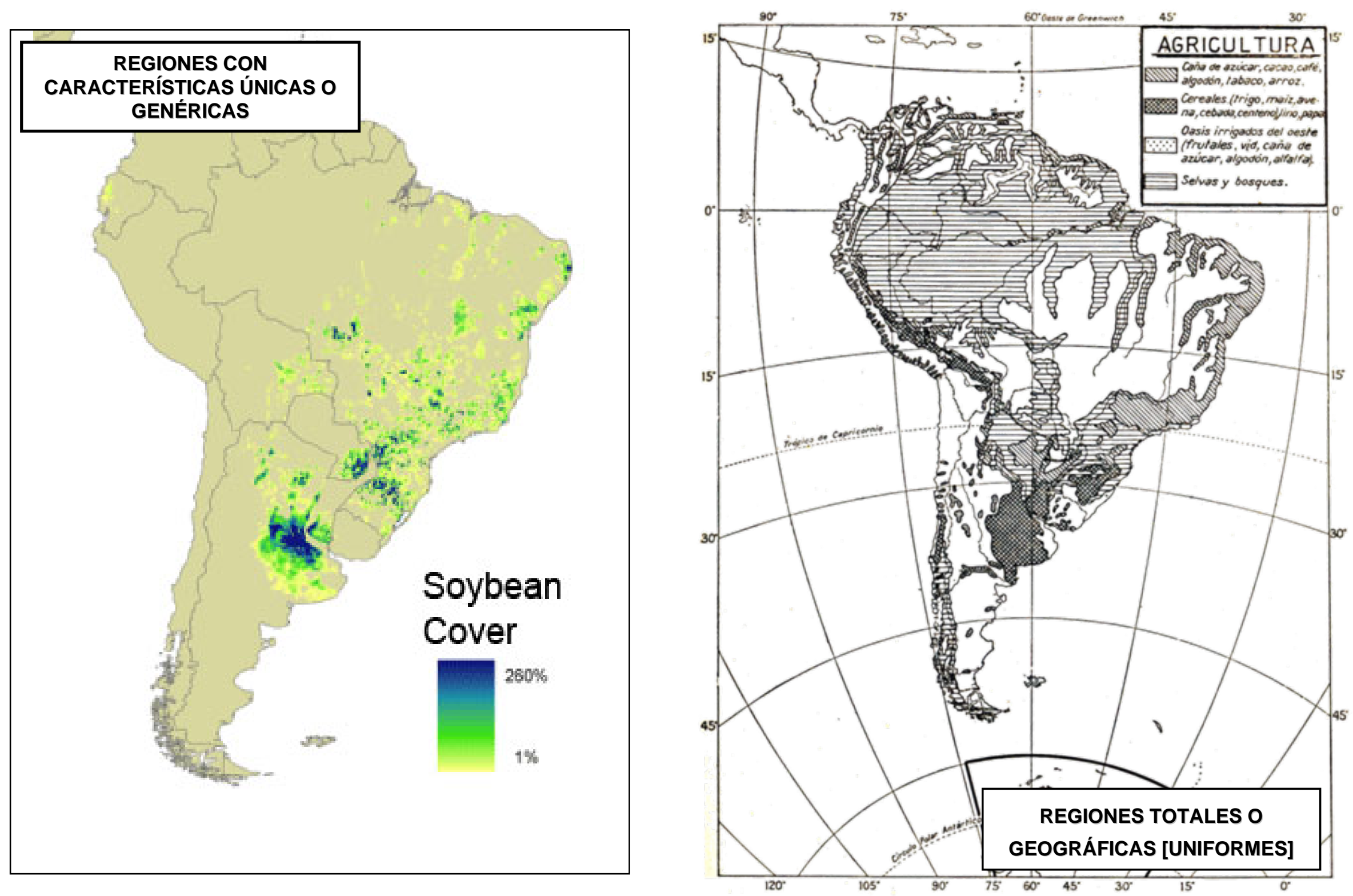

Publicado en formato digital: Prof. Jorge Alfredo ALBERTO y Prof. Marcelo Aníbal MIGNONE. REGIÓN. CONCEPTO CRÍTICO PARA SU DELIMITACIÓN. TIPOS DE REGIONES. Resúmenes. Revista Geográfica Digital.IGUNNE. Facultad de Humanidades. UNNE. Año 9 . №17. Enero -Junio 2012.

Resistencia, Chaco. En: http://hum.unne.edu.ar/revistas/geoweb/default.htm 


\section{REGIONES CON CARACTERÍSTICAS ÚNICAS O GENÉRICAS}

\section{Corn for Grain 2010 \\ Production by County for Selected States}

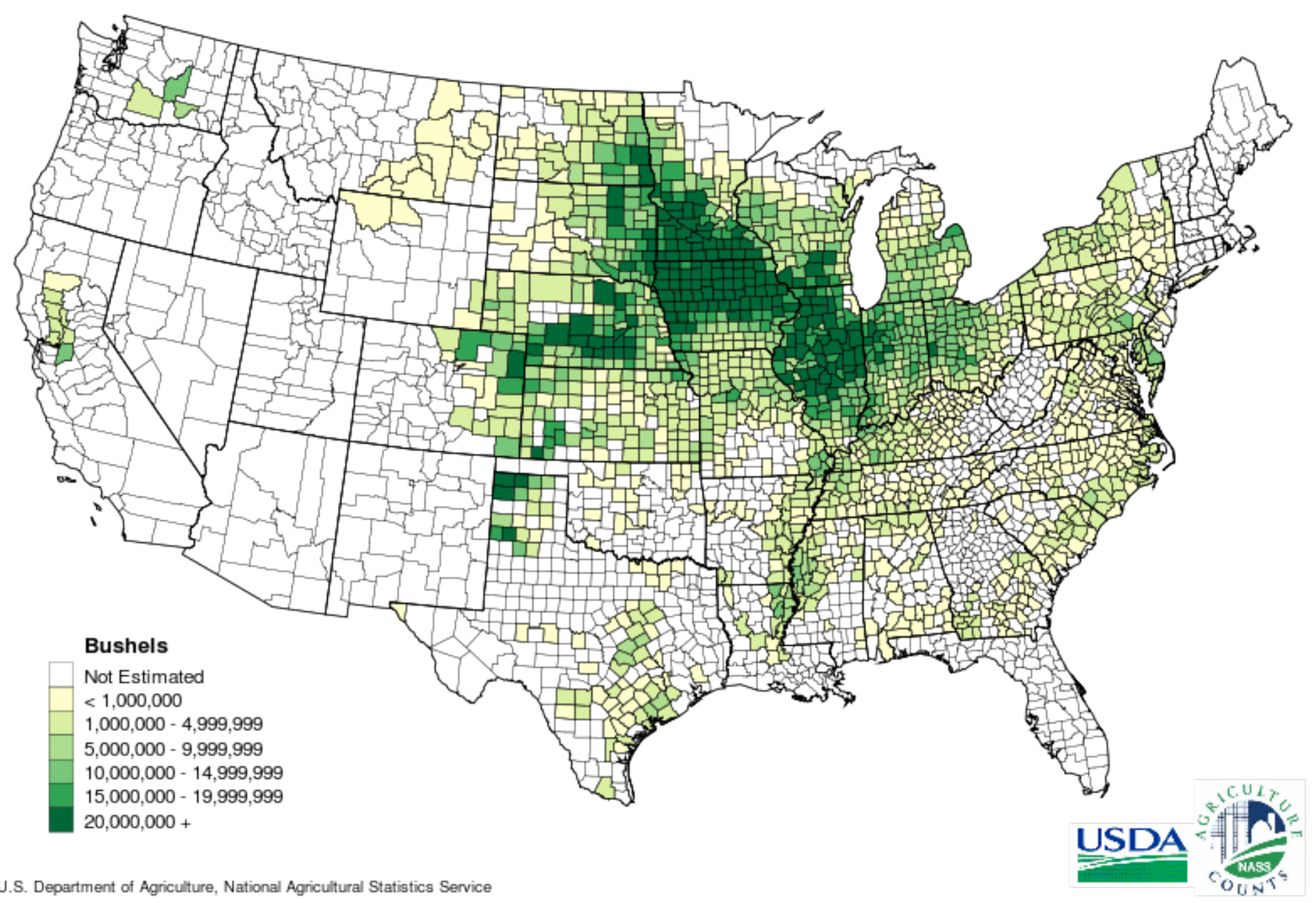
TIPOS DE REGIONES. Resúmenes. Revista Geográfica Digital.IGUNNE. Facultad de Humanidades. UNNE. Año 9. N¹7. Enero -Junio 2012. 


\section{(1) Les transports}

\section{REGIONES TOTALES O GEOGRÁFICAS [NODAL]}

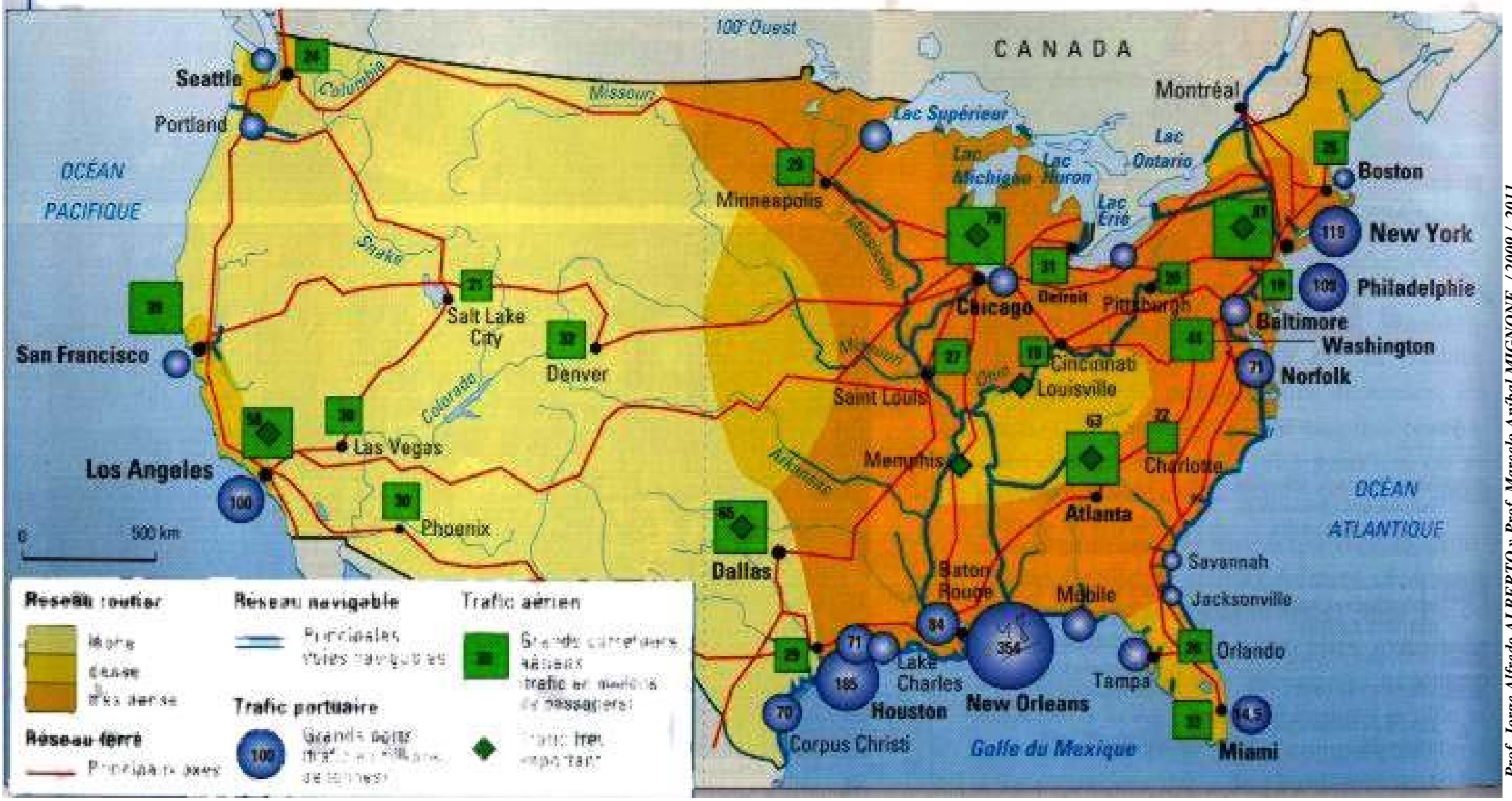

Publicado en formato digital: Prof. Jorge Alfredo ALBERTO y Prof. Marcelo Aníbal MIGNONE. REGIÓN. CONCEPTO CRÍTICO PARA SU DELIMITACIÓN. TIPOS DE REGIONES. Resúmenes. Revista Geográfica Digital.IGUNNE. Facultad de Humanidades. UNNE. Año 9 . N017. Enero -Junio 2012.

Resistencia, Chaco. En: http://hum.unne.edu.ar/revistas/geoweb/default.htm 
TIPOS DE REEGIONES: Cualidades del Espacio

\section{Preston James}

\section{La REGIÓN es una GENERALIZACIÓN GEOGRÁFICA.}

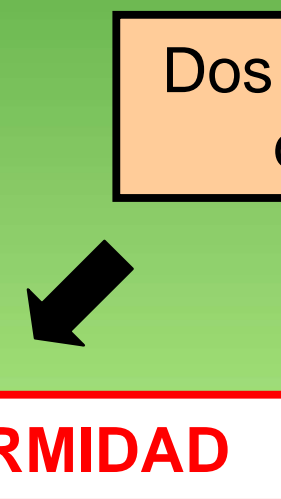

del espacio

\section{UNIFORMIDAD}

\section{FUNCIONALIDAD}

\section{Regiones HOMOGENEAS O UNIFORMES}

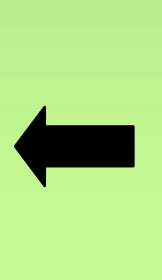

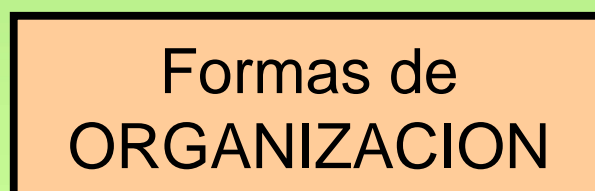

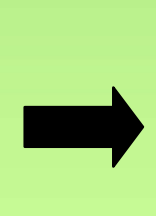

sustentado en la teoría

\section{REGIONES}

FUNCIONALES 


\section{TUPOS DE REGIONES: Con Objetivos Determinados}

\section{J. Boudeville}

REGIONES de planificación, con objetivos determinados.

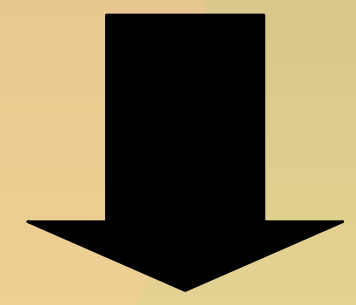

\section{REGIÓN PLAN O PROGRAMA}




\section{JPOS DE REG|ONES}

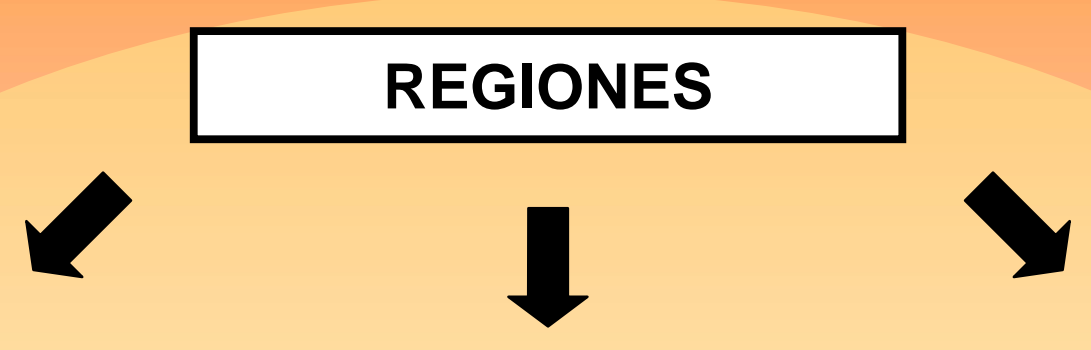

HOMOGENEAS O UNIFORMES

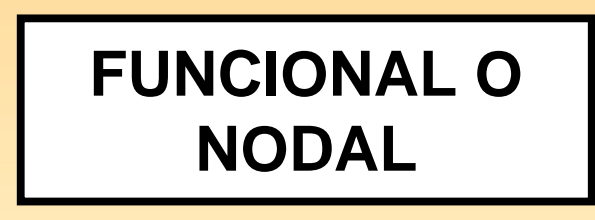

T

REGIONES desde la

Teoría de la Geografía

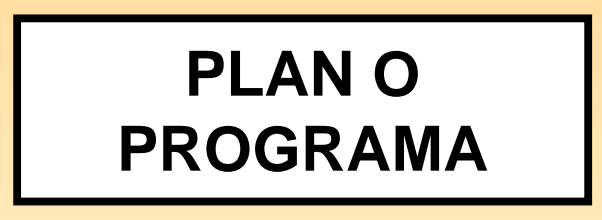

$\mathbf{T}$

REGIÓN desde

la voluntad

política 
IG Revista Geográfica Digital. IGUNNE. Facultad de Humanidades. UNNE. Año 9. №17. Enero - Junio 2012. ISSN 1668-5180 Resistencia, Chaco

\section{TIPOS DE REGIONES: HOMOGENEAS O UNIFORMES}

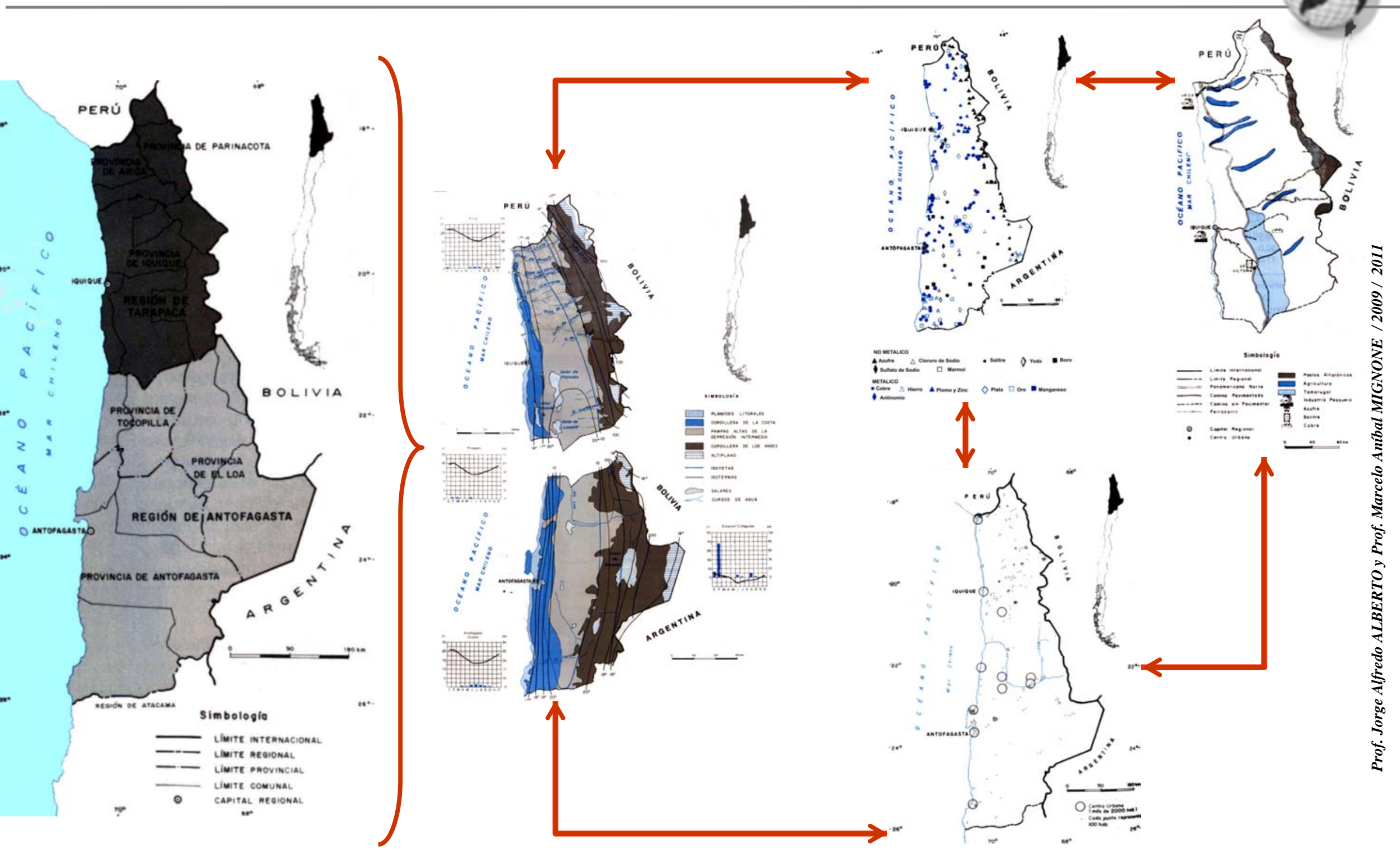

Publicado en formato digital: Prof. Jorge Alfredo ALBERTO y Prof. Marcelo Aníbal MIGNONE. REGIÓN. CONCEPTO CRÍTICO PARA SU DELIMITACIÓN. TIPOS DE REGIONES. Resúmenes. Revista Geográfica Digital.IGUNNE. Facultad de Humanidades. UNNE. Año 9 . No17. Enero -Junio 2012.

Resistencia, Chaco. En: http://hum.unne.edu.ar/revistas/geoweb/default.htm 
$\mathrm{IG}_{\mathrm{U}}$ Revista Geográfica Digital. IGUNNE. Facultad de Humanidades. UNNE. Año 9. №17. Enero - Junio 2012. ISSN/29-5180 Resistencia, Chaco

TIPOS DE REGIONES: FUNCIONAL O NODAL

Región Metropolitana de Santiago

Principal Centro de contacto del país con el exterior.

Capital político - administrativa del país.

Centro nacional de integración y articulador geoeconómico de todo el territorio nacional.

Mayor núcleo demográfico, financiero, industrial, comercial y cultural del país.

Publicado en formato digital: Prof. Jorge Alfredo ALBERTO y Prof. Marcelo Aníbal MIGNONE. REGIÓN. CONCEPTO CRÍTICO PARA SU DELIMITACIÓN. TIPOS DE REGIONES.

Resúmenes. Revista Geográfica Digital.IGUNNE. Facultad de Humanidades. UNNE. Año 9.

No17. Enero - Junio 2012. Resistencia, Chaco. En:

http://hum.unne.edu.ar/revistas/geoweb/default.htm
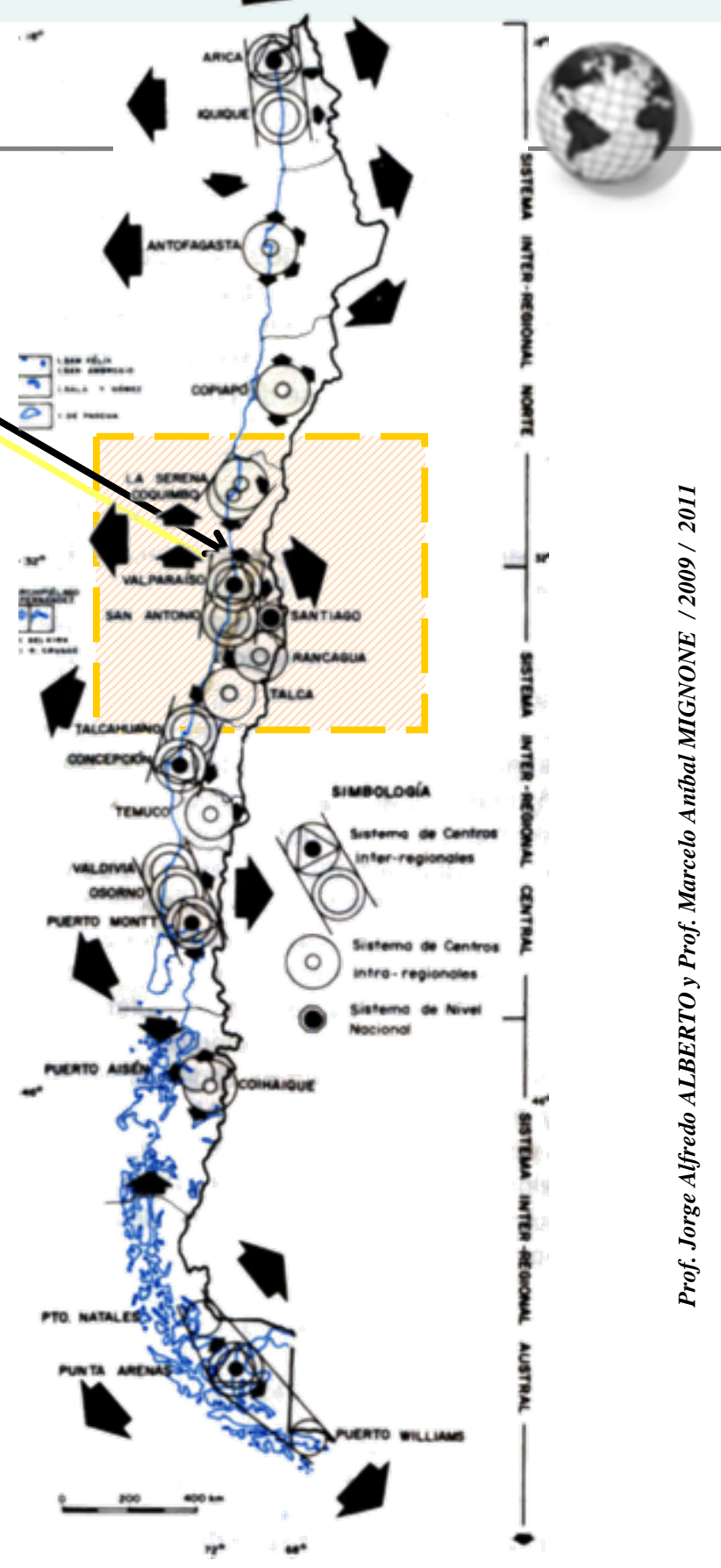
IG Revista Geográfica Digital. IGUNNE. Facultad de Humanidades. UNNE. Año 9. №17. Enero - Junio 2012. ISSN $1668-5180$ Resistencia, Chaco

\section{TIPOS DE REGIONES: PLAN O PROGRAMA}
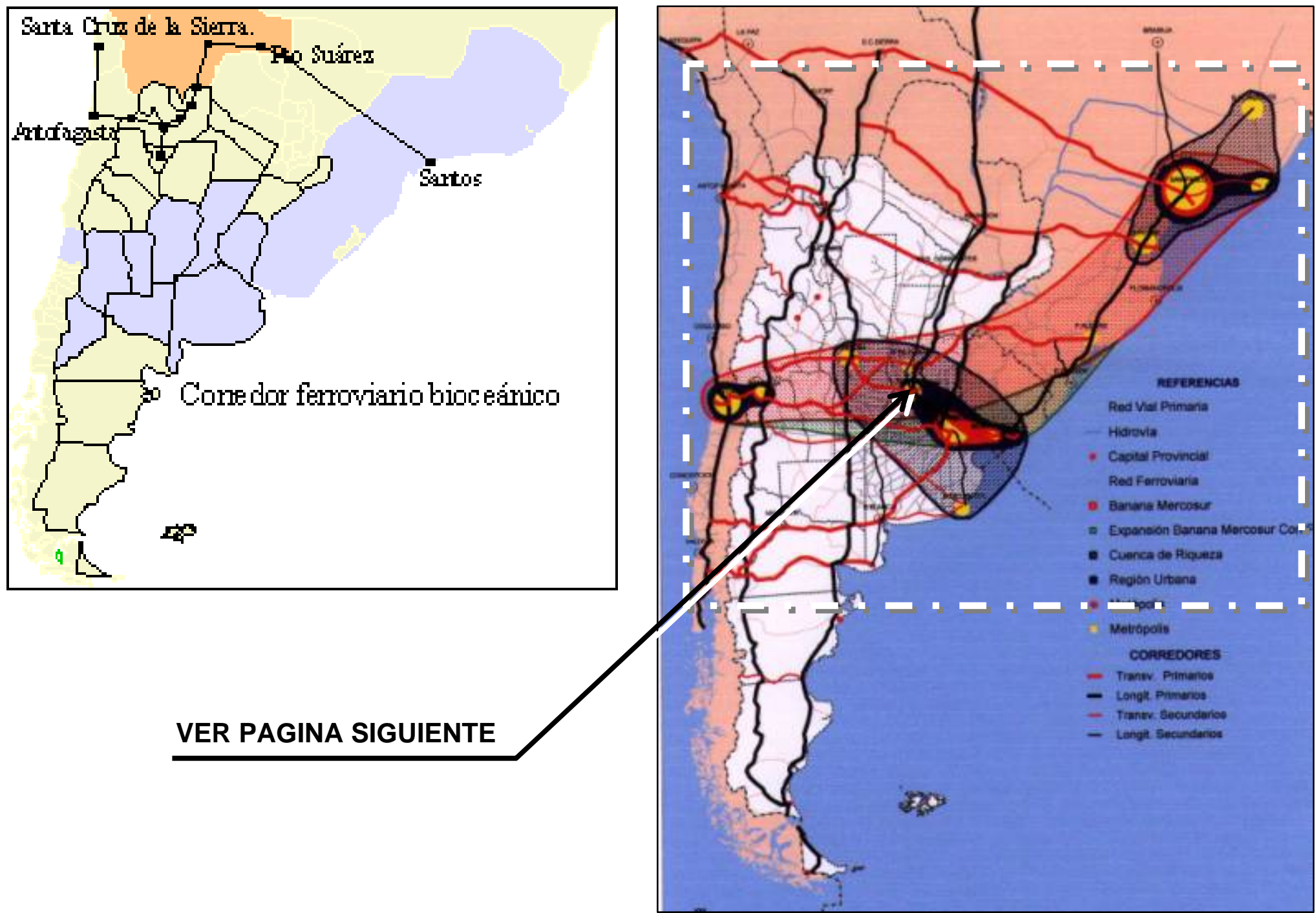

Publicado en formato digital: Prof. Jorge Alfredo ALBERTO y Prof. Marcelo Aníbal MIGNONE. REGIÓN. CONCEPTO CRÍTICO PARA SU DELIMITACIÓN. TIPOS DE REGIONES. Resúmenes. Revista Geográfica Digital.IGUNNE. Facultad de Humanidades. UNNE. Año 9. N¹7. Enero -Junio 2012.

Resistencia, Chaco. En: http://hum.unne.edu.ar/revistas/geoweb/default.htm 


\section{TIPOS DE REGIONES: PLAN O PROGRAMA}

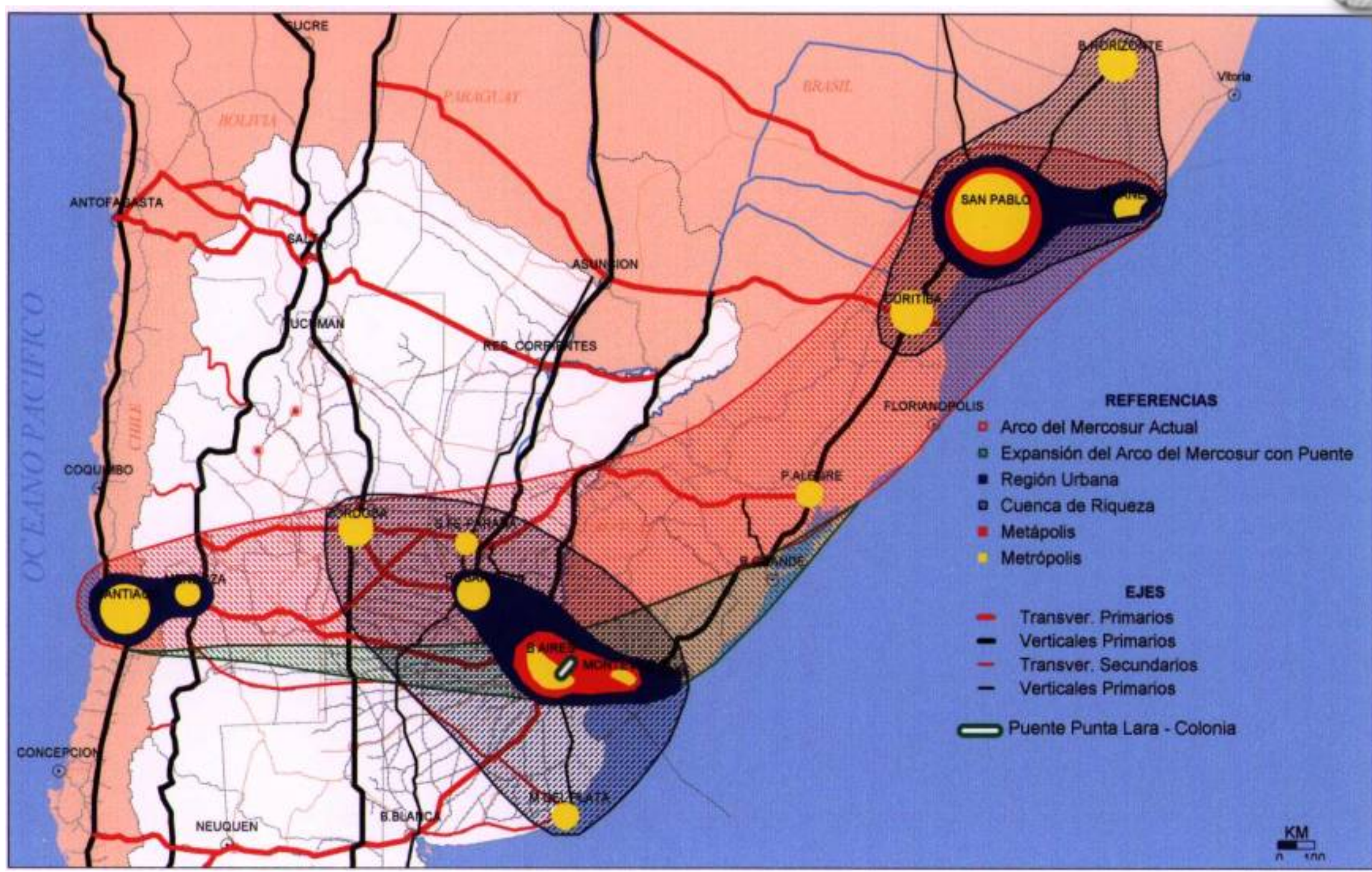

Publicado en formato digital: Prof. Jorge Alfredo ALBERTO y Prof. Marcelo Aníbal MIGNONE. REGIÓN. CONCEPTO CRÍTICO PARA SU DELIMITACIÓN. TIPOS DE REGIONES. Resúmenes. Revista Geográfica Digital.IGUNNE. Facultad de Humanidades. UNNE. Año 9. N¹7. Enero -Junio 2012.

Resistencia, Chaco. En: http://hum.unne.edu.ar/revistas/geoweb/default.htm 


\section{CAMINOS Y ETAPAS PARA LLEVAR ADELANTE UN PROCESO DE REGIONALIZACIÓN}
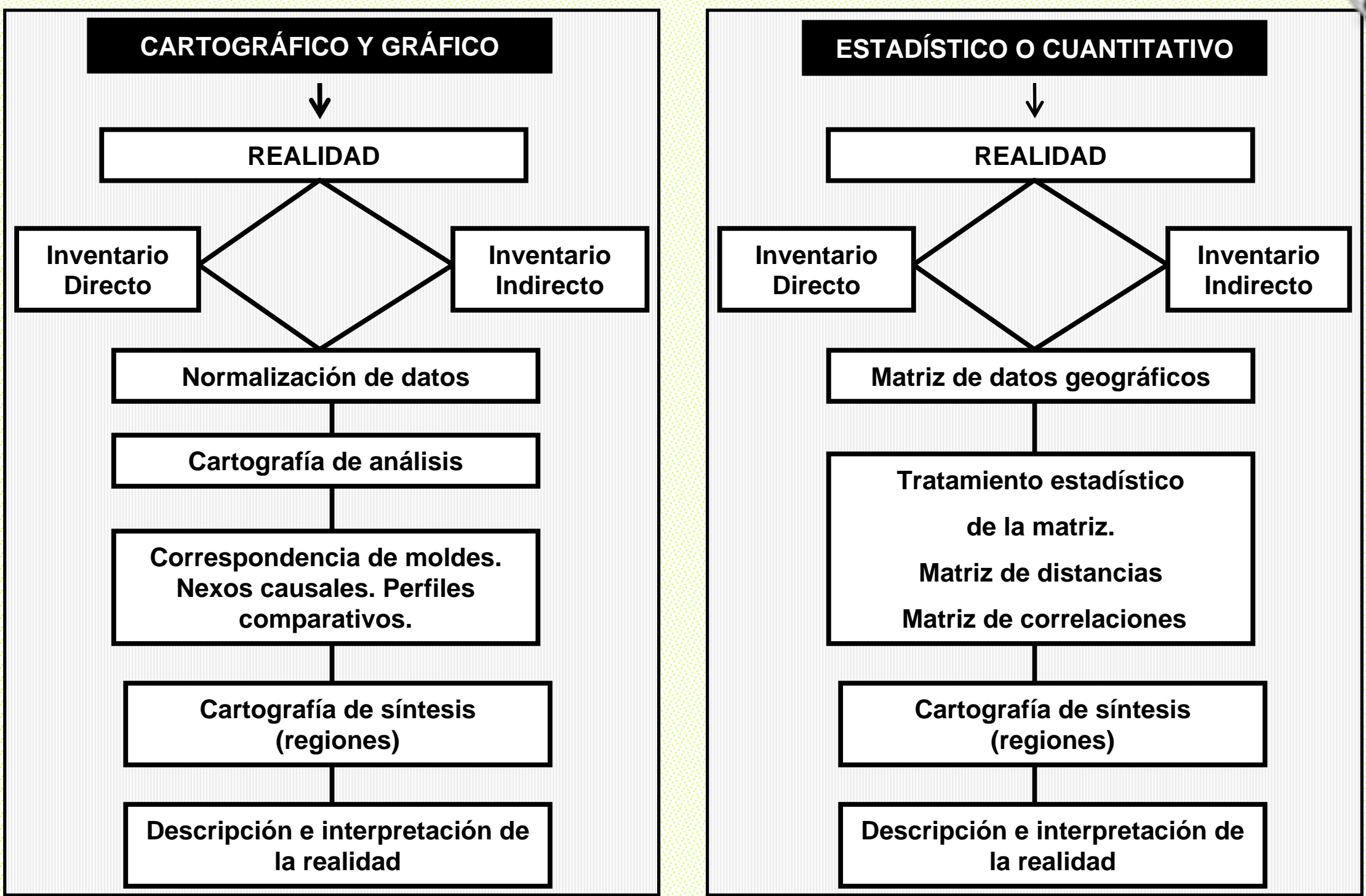

Publicado en formato digital: Prof. Jorge Alfredo ALBERTO y Prof. Marcelo Aníbal MIGNONE. REGIÓN. CONCEPTO CRÍTICO PARA SU DELIMITACIÓN. TIPOS DE REGIONES. Resúmenes. Revista Geográfica Digital.IGUNNE. Facultad de Humanidades. UNNE. Año 9 . No17. Enero - Junio 2012. Resistencia, Chaco. En: http://hum.unne.edu.ar/revistas/geoweb/default.htm 


\section{GUÍA DE LECTURA:}

\section{Análisis de los Conceptos, Región y Tipo de Región}

\section{UNIVERSIDAD NACIONAL DEL NORDESTE FACULTAD DE HUMANIDADES CÁTEDRA GEOGRAFÍA DE AMERICA}

\section{Región. Tipo de Región. Criterios.}

Objetivos:

- Afianzar contenidos conceptuales referidos a región y tipo de región.

- Diferenciar los criterios para caracterizar una región peculiar, haciendo uso de material bibliográfico, gráfico, cartográfico e ilustraciones

Actividades:

1. Lea detenidamente los siguientes textos y relaciónelos con lo visto en la Unidad Temática 1 del programa de la Cátedra Geografía de América

1.1. "La regionalización es un medio para alcanzar un fin, no un fin en si mismo" CRIGG (1974) ¿Qué quiere expresar el autor con esta idea? Argumente la repuesta.

1.2. "Toda región supone un territorio delimitado y continuo de extensión variable, caracterizado por una peculiar combinación de elementos físicos y humanos dotados de ciertos atributos (tamaño y forma) que le otorgan una personalidad propia y diferenciada" Méndez \& Molinero (1994).

¿Qué criterios utiliza el autor para dar una definición de región? Explíquelos. 
1.3. Complete el siguiente cuadro teniendo en cuenta los diferentes tipos de Regiones brindadas en la teoría de la cátedra y explique los criterios tenidos en cuenta para su delimitación.

\begin{tabular}{l} 
REGION HOMOGÉNEA \\
O UNIFORME \\
\hline
\end{tabular}

\begin{tabular}{l} 
REGION FUNCIONAL \\
O NODAL \\
\hline
\end{tabular}

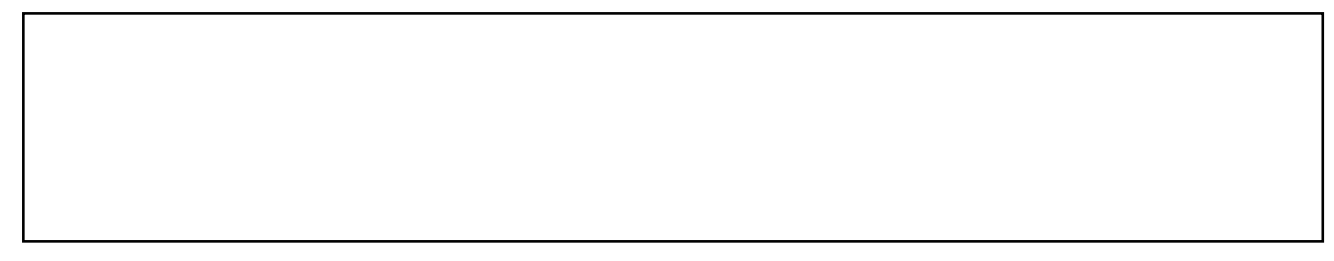

\begin{tabular}{|l|}
\hline REGION PLAN O \\
PROGRAMA \\
\hline
\end{tabular}

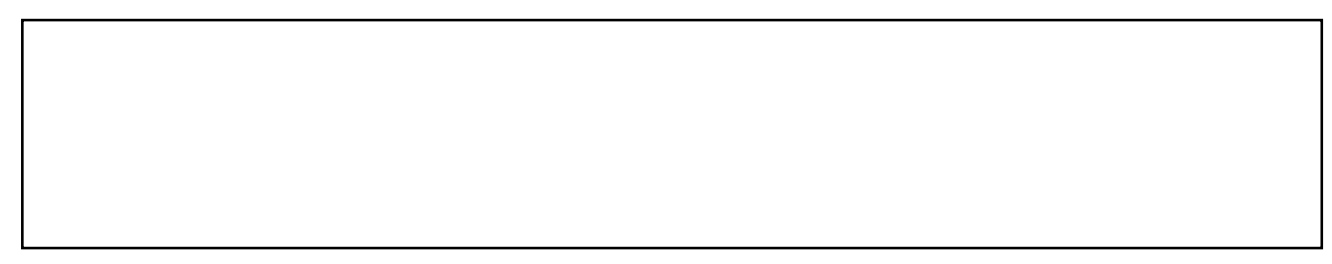


2. Reconozca en estos mapas a qué tipo de región pertenecen según la clasificación dada en el cuadro anterior. Indique y explique los criterios tenidos en cuenta para definir las regiones.
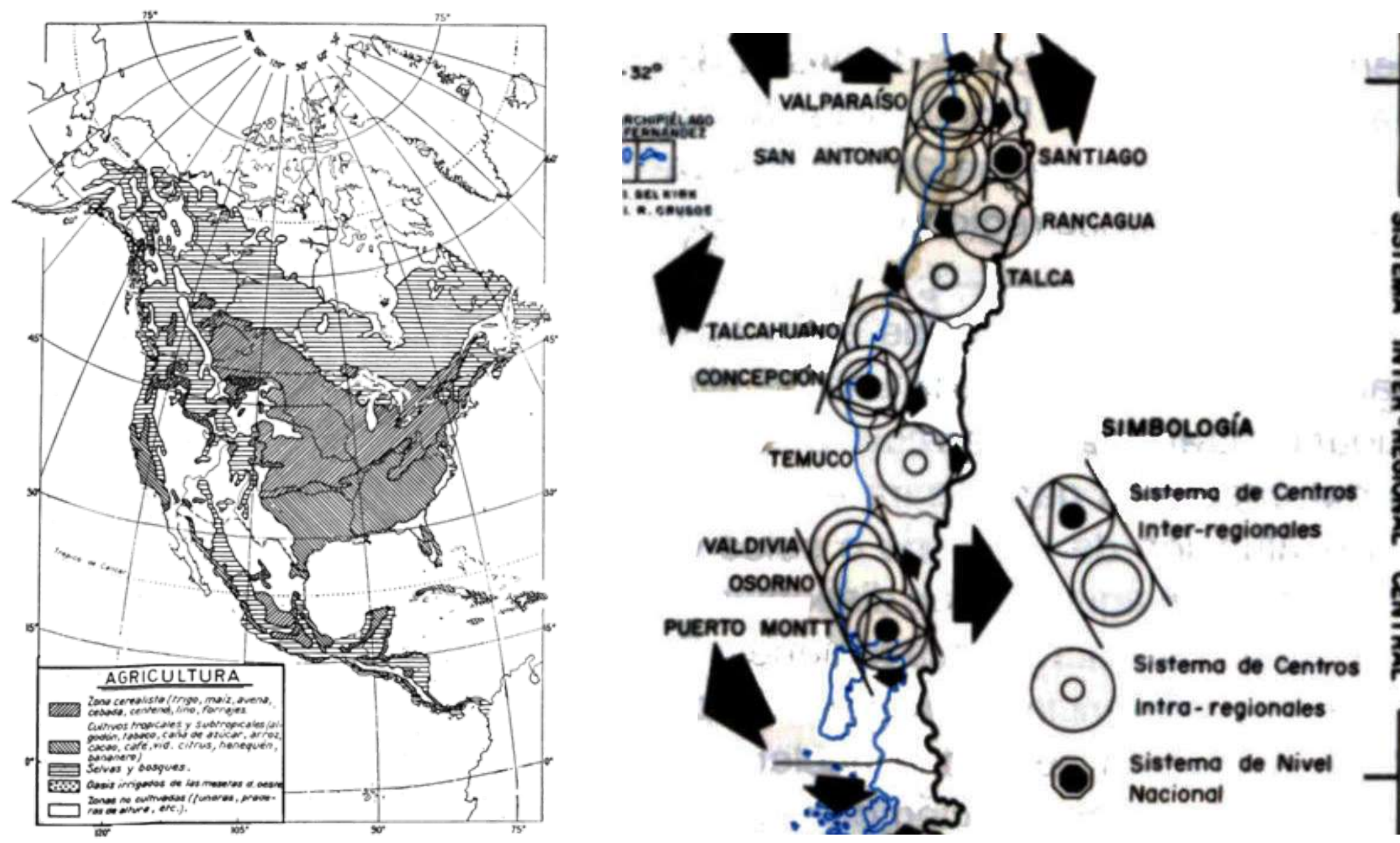

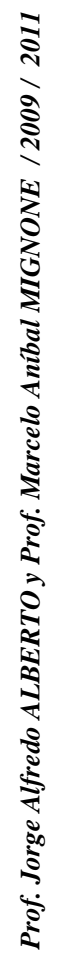

Publicado en formato digital: Prof. Jorge Alfredo ALBERTO y Prof. Marcelo Aníbal MIGNONE. REGIÓN. CONCEPTO CRÍTICO PARA SU DELIMITACIÓN. TIPOS DE REGIONES. Resúmenes. Revista Geográfica Digital.IGUNNE. Facultad de Humanidades. UNNE. Año 9. №17. Enero -Junio 2012. Resistencia, Chaco. En: http://hum.unne.edu.ar/revistas/geoweb/default.htm 


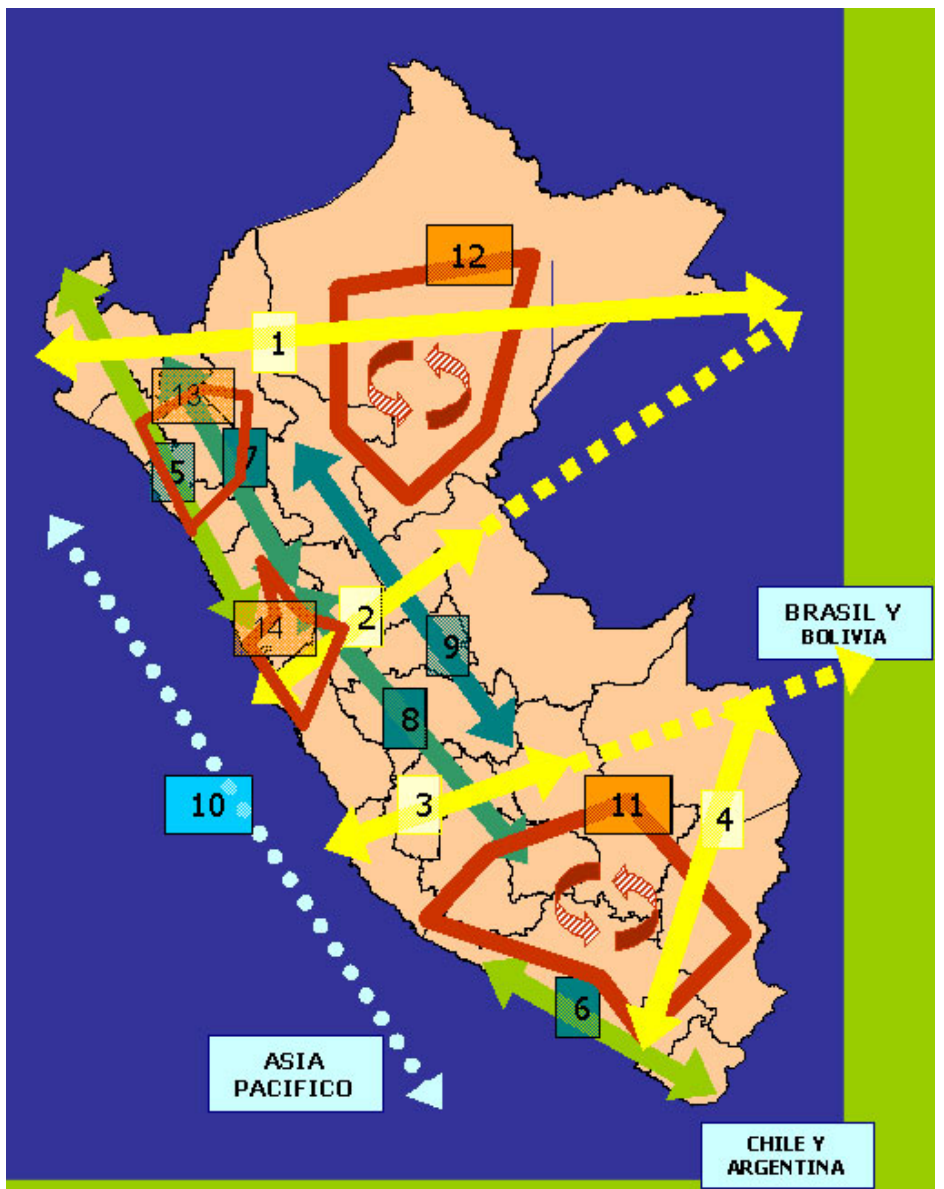

1. Corredor Bioceánico Norte Oriente

2. Corredor Bioceánico Central

3. Corredor Energético Bioceánico Centro Sur

5. Eje Agroindustrial Norte

.

10. Eje Mar Territorial y Pesca Continental

11. Circuito Turístico Sur Altiplano

12. Circuito Turístico Fluvial Amázonico 
arte de synthèse : l'espace américain

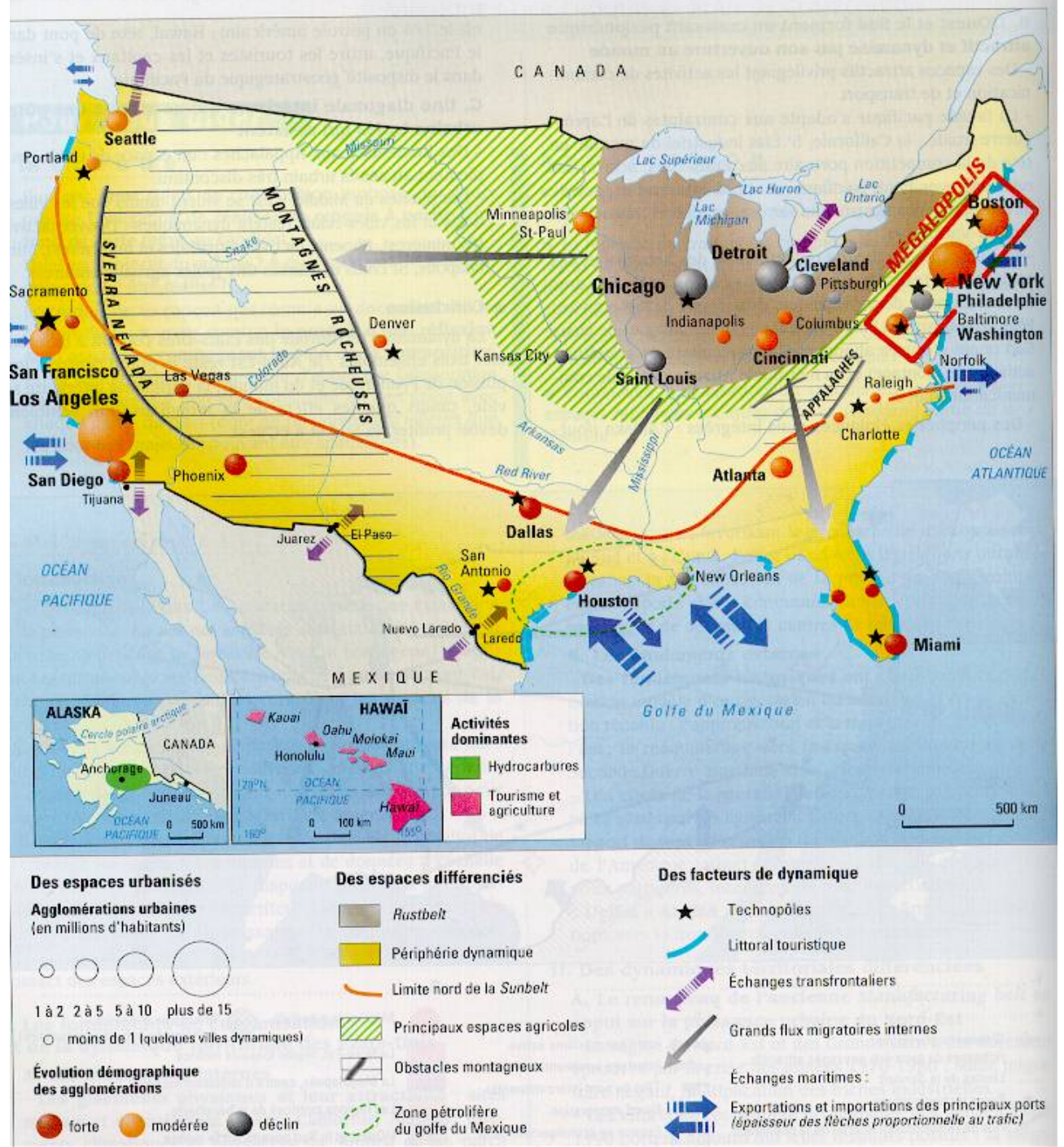

3. En relación a la carta síntesis de los Estados Unidos, ¿Qué elementos y fenómenos (tanto naturales como antrópicos) fueron tenidos en cuenta para su elaboración? ¿Qué tipo de regiones se obtienen con dichos datos según los criterios analizados?. ¿Por qué?

4. Teniendo en cuenta lo observado y analizado con anterioridad, responda: ¿Por qué la región se considera una síntesis del espacio geográfico?. 
IG Revista Geográfica Digital. IGUNNE. Facultad de Humanidades. UNNE. Año 9. №17. Enero - Junio 2012. ISSN 1668-5180 Resistencia, Chaco

\section{Bibliografía recomendada para consulta:}

SPORK. J.A. (1964). "Ensayo de definición y clasificación de las "regiones" en Geografía". Traducción Manoiloff, Raul O.A., Martinez, C. R. Serie Traducciones 1. Facultad de Humanidades. UNNE. Pp. 17.

JULLIARD, E. (1962). "La Región: Ensayo y definición ". Traducción Manoiloff, R. O.A., Martinez, C. R. Serie Traducciones 2. Facultad de Humanidades. UNNE. Pp. 22.

BRUNIARD, E.D. (1995). “ Las Regiones Homogéneas en la Geografía Humana (Guía de trabajos prácticos)". En Revista Nordeste $2^{\mathrm{a}}$ Época. Serie Docencia $\mathrm{n}^{\circ} 1$. Facultad de Humanidades. UNNE. Pp. 38.

OLIVER DOLFUS (1978). "El análisis geográfico" Colección ¿Qué sé? Nueva Serie. Oikos

Tau. Barcelona (España). Pp. 135

Tiempo: 1 modulo de clase práctica (3 horas cátedras de 40` cada una)

Criterios de evaluación:

-Precisión conceptual.

-Integración de conceptos.

-Presentación en tiempo y forma de la producción escrita.

-Prolijidad en la presentación de la producción escrita.

-Correcta redacción y ortografía. 